\title{
Elevated Serum Lipoprotein (a) Levels Associated with Ulcerative Colitis in a Young Japanese Patient
}

\author{
Shigeharu Kawabata, Shuichi Katagiri, Hiroshi Negoro, Akira Nogami, \\ Iwao YabuUchi, Masahiro Gomi, Ryoichi ArImA* and Seiichiro TARUI
}

\begin{abstract}
Thromboembolism has been shown to play a role in the pathogenesis of inflammatory bowel disease (IBD). A possibility exists that lipoprotein (a) [Lp(a)], a newly-discovered prothrombotic factor, also participates in the development of at least some cases of IBD. Marked elevation of serum Lp(a) levels was observed in a young patient with ulcerative colitis. A biopsy specimen of the rectal mucosa showed findings compatible with ulcerative colitis, as well as small vessel thrombus occurring within the muscularis mucosa in the rectum. Serum Lp(a) levels were markedly elevated on admission ( $71 \mathrm{mg} / \mathrm{dl}$ ), with a gradual decrease to $46 \mathrm{mg} / \mathrm{dl}$ on discharge. Moreover, serum $\mathrm{Lp}(\mathrm{a})$ levels decreased in parallel with clinical improvement. In the quiescent clinical stage, no small vessel thrombus was observed in the mucosa on follow-up colonoscopy. The association between IBD and hyper-Lp(a)-emia would be presumable but it has been, to our knowledge, previously unreported. The case reported here would be the first young patient, suggesting the presence of hyper-Lp(a)-emia and small vessel thrombus formation occurring in association with the development of ulcerative colitis.
\end{abstract}

(Internal Medicine 36: 389-391, 1997)

Key words: inflammatory bowel disease (IBD), lipoprotein (a) [Lp(a)], hyper-Lp(a)-emia, small vessel thrombus, small vessel thrombosis, hypercoagulation, prothrombotic state

\section{Introduction}

The apparent association between thromboembolism and inflammatory bowel disease (IBD) has been described more than half a century ago (1-3). Recently small vessel thrombosis has been implicated as rather an etiological factor in Crohn's disease (4). It has been postulated that lipoprotein (a) [Lp(a)] has both prothrombotic and proatherosclerotic actions, through its plasminogen-like properties and low density lipoprotein (LDL)-like characteristics of apo(a) (5). We report a young patient with ulcerative colitis, who had marked serum Lp(a) levels with small vessel thrombus in the rectal mucosa.

\section{Case Report}

A 20-year-old male patient with a history of ulcerative colitis since 1988 was admitted in September 1994 to our hospital because of frequent diarrhea containing blood. He had been treated intermittently with salazosulfapyridine and/or corticosteroids. On admission, laboratory tests revealed a Creactive protein (CRP) of $0.6 \mathrm{mg} / \mathrm{dl}$, fibrinogen of $266 \mathrm{mg} / \mathrm{dl}$, prothrombin time of $93 \%$, and hepaplastin test of $90 \%$. Platelet count was $236,000 / \mathrm{mm}^{3}$ and erythrocyte sedimentation rate was $8 \mathrm{~mm} / \mathrm{h}$. Colonoscopy showed moderately active ulcerative colitis from the rectum to the left transverse colon (Fig. 1). A mucosal biopsy specimen in the active stage showed moderately inflamed, erosive and edematous colorectal mucosa with mild glandular and goblet cell depletion (Fig. 2). Small vessel thrombus occurring within the muscularis mucosa was also revealed in the specimen (Fig. 2). The administration of corticosteroids (prednisolone $20 \mathrm{mg}$ ) and salazosulfapyridine $4.0 \mathrm{~g}$ per day resulted in general improvement with reduction of the stool frequency and bleeding episodes, which was in parallel with the gradual decrease in serum $L p(a)$ levels $(71,59,54$, $46 \mathrm{mg} / \mathrm{dl}$ ) (normal value; less than $40 \mathrm{mg} / \mathrm{dl}$, with the average of $18 \mathrm{mg} / \mathrm{dl}$ ) (Fig. 3). On the other hand, the clinical course of serum CRP levels (normal value; less than $0.3 \mathrm{mg} / \mathrm{dl}$ ) showed a transient rise in the initial period of admission and thereafter maintained normal levels during admission (Fig. 3). In the quiescent clinical stage after discharge, no small vessel thrombus was observed in the rectal mucosa on follow-up colonoscopy. At the same time, serum $L p(a)$ levels were low $(41 \mathrm{mg} / \mathrm{dl})$ compared with those of the active stage. However, serum Lp(a) levels were still higher than the normal value. Furthermore, the 


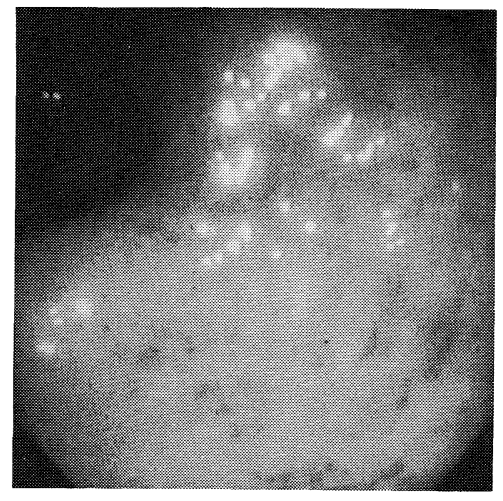

Figure 1. Moderate active proctitis in ulcerative colitis.
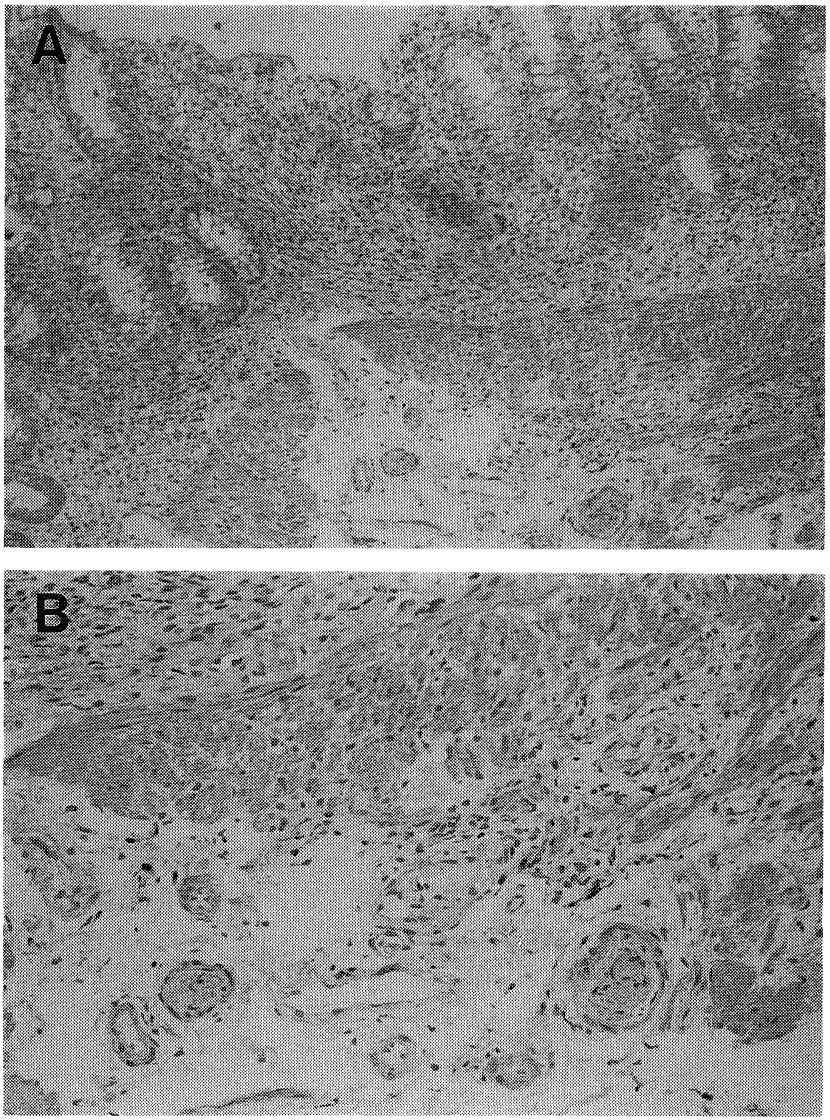

Figure 2. Histological analysis showing small vessel thrombus occurring within the muscularis mucosa in the rectum (HE stain, A: $\times 33, \mathrm{~B}: \times 66)$.

examination of serum $\mathrm{Lp}$ (a) phenotype analysis by sodium dodecyl sulfate-gel electrophoresis (SDS-PAGE) using antiapo(a) and anti-apo B-100 antibodies revealed small size $L p(a)$ patterns, suggesting that hyper- $\mathrm{Lp}(\mathrm{a})$-emia in this patient is genetically determined (Fig. 4). Neither arteriosclerotic change of vessel nor vasculitis was observed.
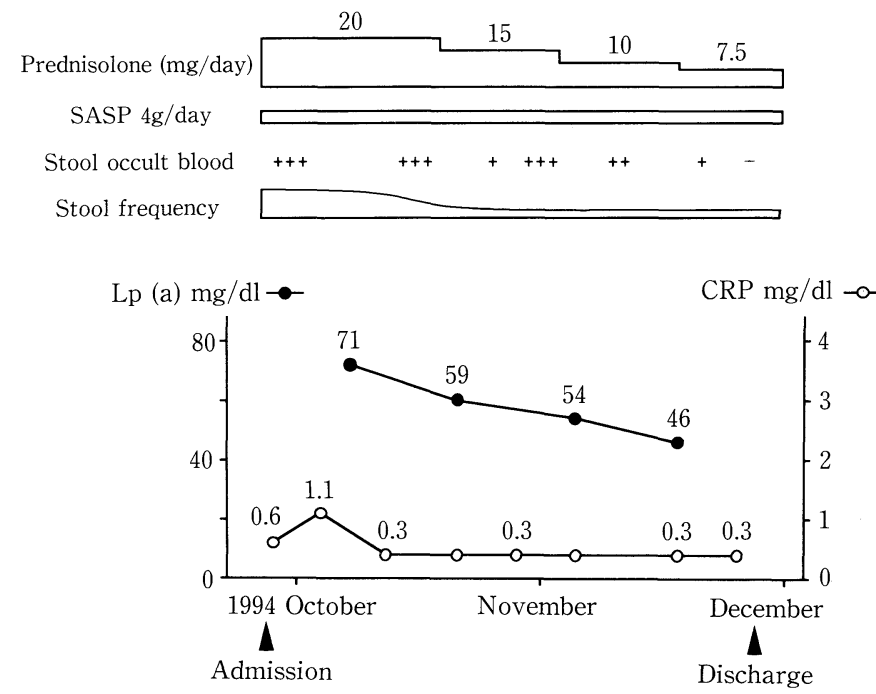

Figure 3. Clinical course during admission. SASP: salazosulfapyridine.

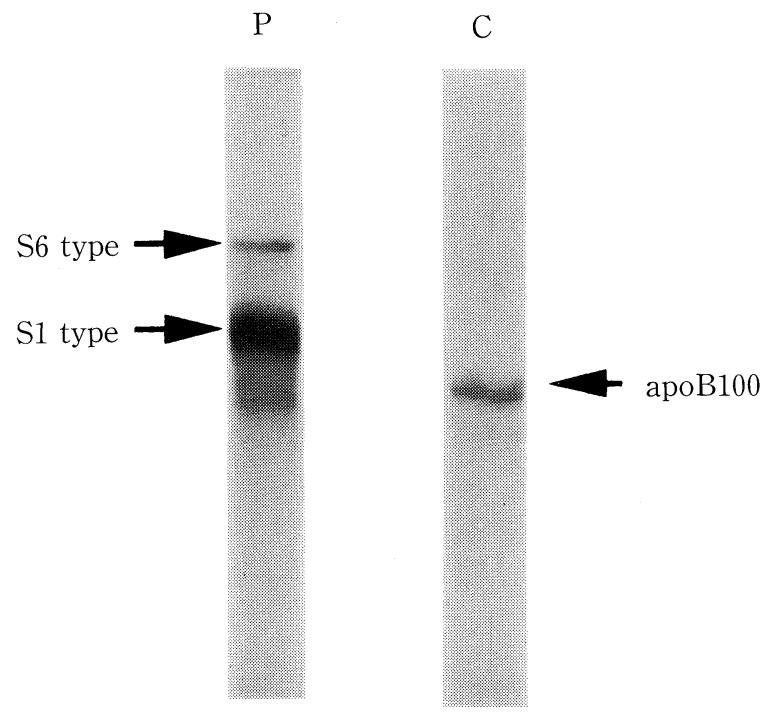

Figure 4. Serum Lp(a) phenotype analysis by SDS-PAGE Patient $(P)$ was detected by anti-apo(a) antibody. Control $(C)$ was detected by anti-apo B-100 antibody. According to their relative mobilities compared with apo B-100, Lp(a) phenotype patterns were categorized into phenotypes $F$ (faster than apo B-100), B (similar to apo B-100), S1, S2, S3, S4, S5, S6, S7, S8 and S9 (slower than apo B-100 by different degrees) and into the respective double-band phenotypes. This patient showed a small size $L p(a)$ phenotype (S1/S6).

\section{Discussion}

Ulcerative colitis is a chronic inflammatory process of unknown etiology. The importance of thromboembolic phenomena in IBD has been focused upon since Bargen and Barker described extensive arterial and venous thrombosis in very ill 
young patients with ulcerative colitis (1). Previous studies have also suggested that hypercoagulation is associated with both Crohn's disease and ulcerative colitis $(6,7)$. Thromboembolic complications have been reported to occur in patients with IBD at rates ranging from 1.2 to $39 \%$, and to be associated with a high mortality $(1,8,9)$. Furthermore, a recent study has shown that as many as $77 \%$ of peripheral venous thrombosis cases occurred spontaneously, although peripheral arterial and portal vein thrombosis were predominantly postsurgical complications in IBD patients (9). These findings strongly suggest that hypercoagulation plays an important role in the pathogenesis of IBD.

$\mathrm{Lp}(\mathrm{a})$, a unique lipoprotein first discovered by Berg (10), has been strongly linked with atherosclerosis and is considered an independent risk factor for myocardial infarction (11-13). More recently, the sequence of apo(a), the characteristic apolipoprotein of $\mathrm{Lp}(\mathrm{a})$, was reported to have a striking homology with human plasminogen (14). Considering the structure clarified, the actions of $\mathrm{Lp}$ (a) could be not only proatherosclerotic but also prothrombotic. In fact, several studies have now shown that $L p(a)$ can compete in vitro with the binding of plasminogen to fibrinogen or to fibrin monomer $(15,16)$. It has also been shown that $L p(a)$ competes for the binding of plasminogen to the plasminogen receptor on endothelial cells and macrophages, at a concentration equal to physiological levels $(17,18)$. These findings suggest that $\mathrm{Lp}(\mathrm{a})$ can induce a prothrombotic state.

In the present case, the coexistence of elevated serum $L p(a)$ levels and small vessel thrombus in the rectal mucosa may have reflected a local prothrombotic state induced by $L p(a)$ in IBD. After the medical treatment with moderate doses of prednisolone, stool frequency and occult blood in stool gradually improved, which was in parallel with the gradual decrease in serum Lp(a) levels. Furthermore, no small vessel thrombus was observed on follow-up colonoscopy during the quiescent stage. These observations show that small vessel thrombus related to elevated serum $L p(a)$ levels took place in active IBD lesions, suggesting that elevated serum $L p(a)$ levels and small vessel thrombus were associated with the development of ulcerative colitis in the present patient. Therefore, even in young patients without arteriosclerosis or vasculitis, hyper-Lp(a)-emia can contribute to thrombotic events, resulting in chronic mucosal inflammation possibly as a result of microvascular injury.

Serum $\operatorname{Lp}(\mathrm{a})$ concentrations are thought to be determined mainly genetically and little influenced by environmental factors. In the present case, the examination of serum $\mathrm{Lp}(\mathrm{a})$ phenotype analysis by SDS-PAGE revealed small size Lp(a) patterns. Moreover, during the quiescent clinical stage, serum $\mathrm{Lp}$ (a) levels were still higher than the normal value, indicating the presence of genetically determined hyper-Lp(a)-emia in this patient. On the other hand, serum $L p(a)$ levels were gradually decreased by the administration of prednisolone. The effect of corticosteroids on serum $\mathrm{Lp}(\mathrm{a})$ levels has not yet been reported, but this observation strongly suggests that the administration of prednisolone decreases serum $\mathrm{Lp}(\mathrm{a})$ levels in parallel with the strength of its anti-inflammatory effects. Taken together, these findings also imply that serum $L p(a)$ levels are in some IBD patients determined not only by genetic factors, but also by acquired factors. $L p(a)$ may participate in the development of at least some cases of IBD via its prothrombotic effects, although direct proof of this is still lacking. The existence of a link between the inhibitory effects of $L p(a)$ on fibrinolysis and systemic hypercoagulation remains to be demonstrated.

In summary, this appears to be the first young case, suggesting the presence of hyper-Lp(a)-emia and small vessel thrombus formation occurring in association with the development of ulcerative colitis. Measurements of serum Lp(a) levels in patients with active IBD may be useful for the prediction of thrombotic events, sometimes leading to grave complication.

Acknowledgements: The authors thank Yoshihiko Otsuka for the data research of $L p(a)$ phenotype analysis.

\section{References}

1) Bargen JA, Barker NW. Extensive arterial and venous thrombosis complicating chronic ulcerative colitis. Arch Intern Med 58: 17, 1936.

2) Ricketts WE, Palmer WL. Complications of chronic nonspecific ulcerative colitis. Gastroenterology 7: 55, 1946.

3) Edwards FC, Truelove SC. The course and prognosis of ulcerative colitis. Gut 5: 1, 1964.

4) Wakefield AJ, Sawyerr AM, Dhillon AP, et al. Pathogenesis of Crohn's disease: multifocal gastrointestinal infarction. Lancet 2: 1057, 1989.

5) Scanu AM, Fless GM. Lipoprotein (a). Heterogeneity and biological relevance. J Clin Invest 85: 1709, 1990.

6) Edwards RL, Levine JB, Green R, et al. Activation of blood coagulation in Crohn's disease. Increased plasma fibrinopeptide A levels and enhanced generation of monocyte tissue factor activity. Gastroenterology 92: 329,1987

7) Webberley MJ, Hart MT, Melikian V. Thromboembolism in inflammatory bowel disease: role of platelets. Gut 34: 247, 1993.

8) Graef V, Baggenstoss AH, Sauer WG, Spittell JA, Minn R. Venous thrombosis occurring in nonspecific ulcerative colitis. Arch Intern Med 117: $377,1966$.

9) Talbot RW, Heppell J, Dozois RR, Beart RW Jr. Vascular complications of inflammatory bowel disease. Mayo Clin Proc 61: 140, 1986.

10) Berg K. A new serum type system in man - the Lp system. Acta Pathol Microbiol Scand 59: 369, 1963.

11) Kostner GM, Avogaro P, Cazzolato G, Marth E, Bittolo-Bon G, Qunici GB. Lipoprotein $L p(a)$ and the risk for myocardial infarction. Atherosclerosis 38: 51, 1981.

12) Armstrong VW, Cremer P, Eberle E, et al. The association between serum $\mathrm{Lp}(\mathrm{a})$ concentrations and angiographically assessed coronary atherosclerosis. Dependence on serum LDL levels. Atherosclerosis 62: 249, 1986.

13) Dahlen GH, Guyton JR, Attar M, Farmer JA, Kautz JA, Gotto AM Jr. Association of levels of lipoprotein (a) Lp(a), plasma lipids, and other lipoproteins with coronary artery disease documented by angiography. Circulation 74: 758, 1986.

14) Mclean JW, Tomlinson JE, Kuang WJ, et al. cDNA sequence of human apolipoprotein (a) is homologous to plasminogen. Nature 330: 132, 1987.

15) Harpel PC, Gordon BR, Parker TS. Plasmin catalyzes binding of lipoprotein (a) to immobilized fibrinogen and fibrin. Proc Natl Acad Sci USA 86: $3847,1989$.

16) Loscalzo J, Weinfeld M, Fless GM, Scanu AM. Lipoprotein (a), fibrin binding, and plasminogen activation. Arteriosclerosis 10: 240, 1990.

17) Miles LA, Fless GM, Levin EG, Scanu AM, Plow EF. A potential basis for the thrombotic risks associated with lipoprotein (a). Nature 339: 301, 1989.

18) Hajjar KA, Gavish D, Breslow JL, Nachman RL. Lipoprotein (a) modulation of endothelial cell surface fibrinolysis and its potential role in atherosclerosis. Nature 339: 303, 1989. 